\title{
Effective Competition, Administrative Guidance, and Collusion in the Telecommunications Sector*
}

\author{
Hong-Seok Bok** and Sangin Park***
}

\begin{abstract}
The regulatory authority of the telecommunications sector in Korea has typically employed explicit or implicit administrative guidance as a means of effective competition. This paper critically reviews an administrative guidance of the Ministry of Information and Communications (the regulatory authority for the telecommunications sector until 2007) through the Korea Fair Trade Commission case of KT Hanaro Telecomm in the fixed-line telecommunications service market. Our analysis indicates that empirical evidence does not support the concerns that motivated the administrative guidance. Instead, it turned out to facilitate collusion between the dominant firm and a fledgling competitor. We suggest an alternative pro-competitive policy that provides a level playing field to fledgling competitors from the beginning and regulates predatory pricing and collusion.
\end{abstract}

Keywords: Effective Competition, Administrative Guidance, Collusion, Level Playing Field, Telecommunications Sector

* The authors are grateful for financial support from KDI (Korea Development Institute). A previous version of this paper was presented at the 2007 KDI International Conference titled "Competition Policy in Regulated Sectors: Focusing on the Institutional Design of the Relationship between Competition Authority and Sectoral Regulators."

** Hong-seok Bok is a Ph.D. candidate of the Graduate School of Public Administration, Seoul National University. His current research interests include communications policy, competition policy. Email: bokong96@hanmail.net.

*** Sangin Park (Ph.D. in Economics, Yale University) is an associate professor of the Graduate School of Public Administration, Seoul National University and also serves as an associate editor of International Journal of E-Government Research. Prior to that, he was an assistant professor of Economics at the State University of New York at Stony Brook (1996-2003), and a Visiting Assistant Professor of Economics at Yale University (Fall 2002). He has published a number of papers in academic journals including Review of Economics and Statistics and Journal of Econometrics and serve as the editor of several books including Strategies and Polices in Digital Convergence. His current research interests include communications policy, competition policy, and e-governance. Dr. Park holds a Ph. D. in Economics from Yale University. Email: sanpark@snu.ac.kr.

Manuscript received April 2008; out for review June 2008; review completed August 2008; accepted October 2008.

The Korean Journal of Policy Studies, Vol. 23, No. 2, 189-200 (2009)

C 2009 by the GSPA, Seoul National University 


\section{INTRODUCTION}

A main policy goal of the Korean regulatory authority in the telecommunications sector- until 2007, the Ministry of Information and Communications (MIC) — has been to promote effective competition. At the same time, MIC preferred facility-based competition to service-based competition since it believed facility investments could have spillover effects on other related industries. Hence, for the promotion of effective competition, MIC allowed companies with facilities to enter the relevant market and then implement explicit and implicit administrative guidance on the dominant firm and its fledgling competitors. The administrative guidance was mainly to set a price floor for the dominant firm, since MIC was concerned about the possibility that the dominant firm might wage aggressive price competition and eventually drive out competitors.

However, as recognized in the field of industrial organizations, the regulation of pricing structures may facilitate collusion between the dominant firm and emerging competitors (see, for instance, Knittel and Stango 2003). Recently, the Korea Fair Trade Commission (KFTC) ruled that KT, the dominant firm in fixed-line telephone service, and Hanaro Telecom, the emerging competitor, colluded to set Hanaro Telecom's prices, which was facilitated by the administrative guidance of MIC at the end of 2002.

Following a review of the case, we will argue that the conditions for an effective competition policy were not met, around the end of 2002, in the market for fixed-line telecommunications service. On the contrary, the MIC's 2002 administrative guidance, which was intended to promote competition, actually facilitated collusion. As a future policy recommendation (for instance, for the Wibro market), we suggest an alternative approach that focuses on creating a level playing field for the incumbent and entrants. Then predatory pricing and collusion can be dealt in the context of competition law.

\section{THE KT-HANARO TELECOMMUNICATIONS CASE}

In order to reduce the gap between the two companies' local call rates, KT and Hanaro Telecomm agreed on June 23, 2003, that in exchange for KT's transfer of 1.2 percent of market share to Hanaro every year until 2007, KT would maintain its rates and Hanaro would either increase or adjust its rates.

KFTC found that this agreement helped the two firms to coordinate their rates and market shares in response to the enforcement of Local Number Portability, and on August 18, 2005, ruled that these actions constituted unfair coordination or collusion. KFTC fined KT 113,048 million Korean won (KRW) and Hanaro 2,155 million KRW. 
KT argued as follows. Hanaro was in a deteriorating situation that might result in its exit from the fixed-line telecommunications service market. In order to rescue Hanaro and promote effective competition, MIC concretely guided KT and Hanaro between October and November 2002. The agreement of June 23, 2003 was the unavoidable result of the two companies' compliance with the MIC's administrative guidance. Hence, their action was lawful and justified under the Monopoly Regulation and Fair Trade Act - and if not, it at least merited a reduction of or exemption from liability. In other words, KT argued that the action was not the type of unfair action that KFTC tries to restrict, but rather complied with the purpose of the Monopoly Regulation and Fair Trade Act because it saved Hanaro, a company that was in financial trouble, from exiting the market. Thus, it promoted effective competition and increased consumer welfare.

KFTC responded as follow. First, KT's assertion that it was following MIC's guidance was irrelevant; KT was acting in its own interest, to prevent loss and maximize profit. Second, MIC's requests were not binding on KT, and the ministry did not offer any follow-up guidance. Third, in order to qualify as a "lawfully fair act" under Article 58 of the Monopoly Regulation and Fair Trade Act, there should be a legal aspect that specifically accepts an exemption from open competition or it should be considered as the necessary minimum act. However, the agreement did not comply with the Telecommunication Business Act, which promotes effective competition. Lastly, even if it might be justifiable to restrict free competition for the sake of effective competition, the specific tactics - such as the artificial price agreement and transfer of market share among competitors-were not justifiable under the Monopoly Regulation and Fair Trade Act.

The argument between KT and the KFTC indicates that the KT-Hanaro agreement was indeed collusive. However, the lawfulness of this agreement seems to depend in compliance with the unavoidable administrative guidance of MIC. This paper is not intended to make a judgment on the lawfulness of the agreement. Instead it uses information from the KT-Hanaro case to critically review MIC's administrative guidance 2002 as a means to promote effective competition.

\section{MIC'S EFFECTIVE COMPETITION POLICY}

MIC's administrative guidance to promote effective competition reflects two concerns. (See, for instance, pages 26, 29, and 31 of the KFTC Decision, 2005.) MIC is concerned, first, that the dominant firm may set a monopoly price that results in welfare losses, and second, that the dominant firm may engage in aggressive pricing and 
thus drive out competitors. Hence, by administrative guidance and price regulation of the dominant firm, MIC aims to reduce the discrepancy of market shares between the dominant firm and its competitors, believing that a smaller discrepancy indicates effective competition.

MIC's first concern assumes that competitors may not be competitive enough to constrain the dominant firm from wielding monopoly power, while the second concern presumes that competitors may not be efficient enough to survive severe price competition. MIC's price regulation and administrative guidance do indeed constitute a managed-market policy, since these two concerns are based on the perception that the market itself does not provide a level playing field and thus the regulator has to manage it in order to keep competition (actually, competitors rather than competition itself) alive.

We will next conduct a reality check to see if these concerns were met in the fixedline telecommunications service market around the end of 2002 when MIC's administrative guidance was implemented.

First, were the emerging competitors able to constrain the monopoly power of KT, the dominant firm? As indicated in figures 1-3, KT's market share steadily declined in terms of subscribers, calling hours, and revenues, while the its competitor, Hanaro,

Figure 1. Market Share-Subscribers

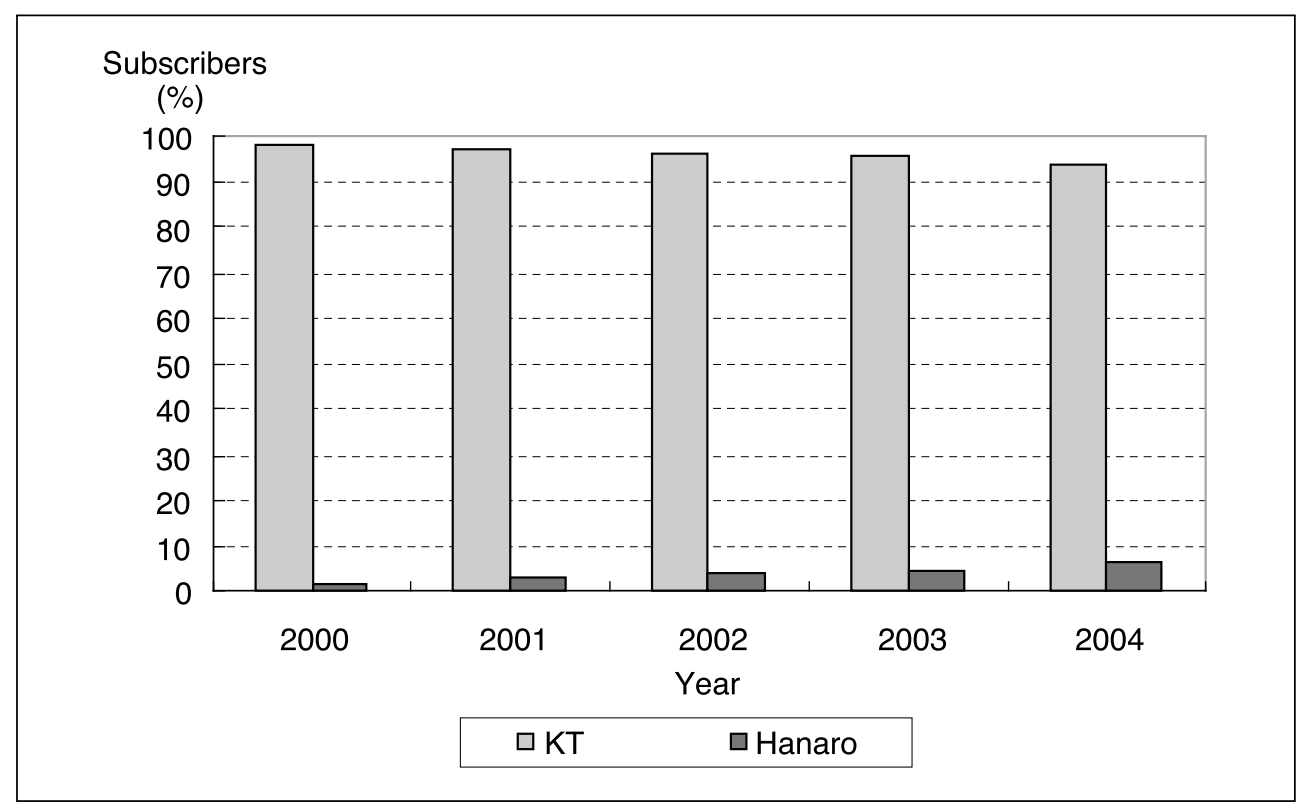

Source: KFTC 
Figure 2. Market Share-Calling Hours

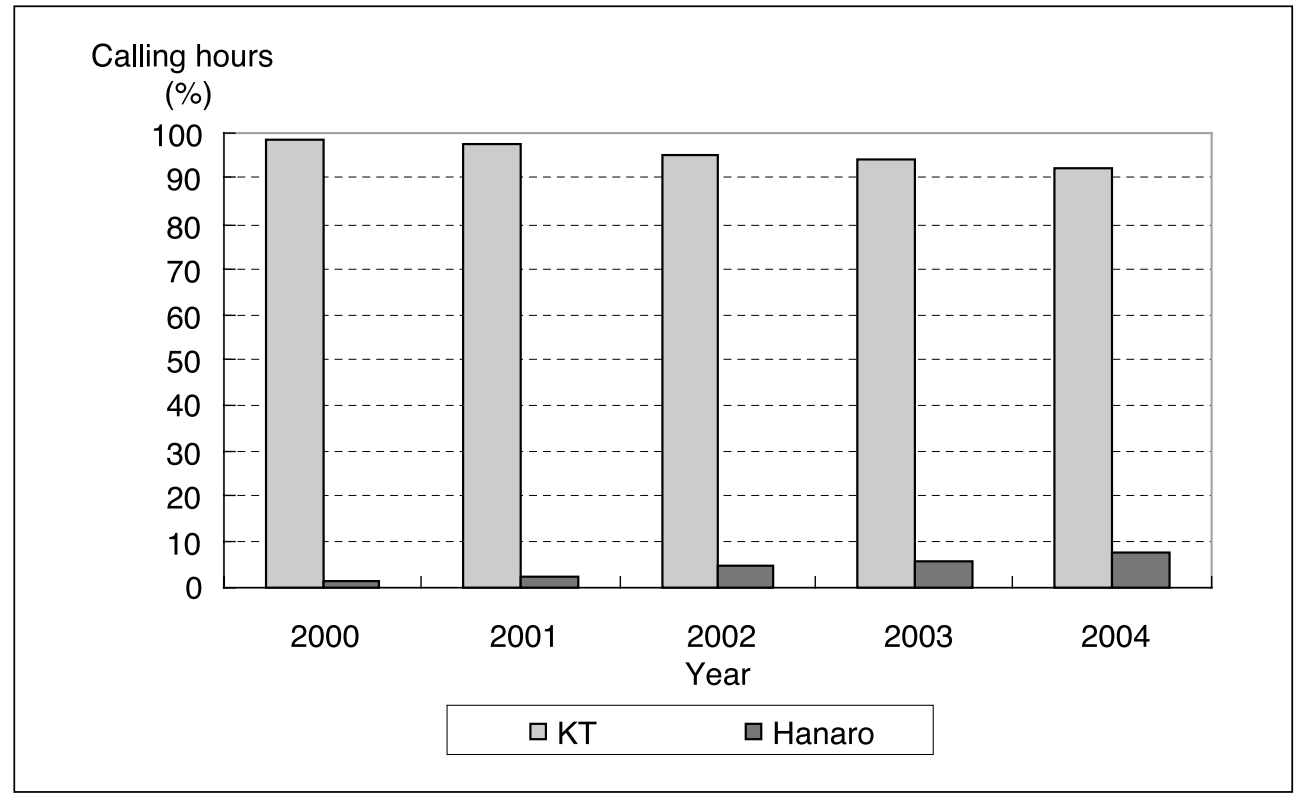

Source: KFTC

Figure 3. Market Share-Revenues

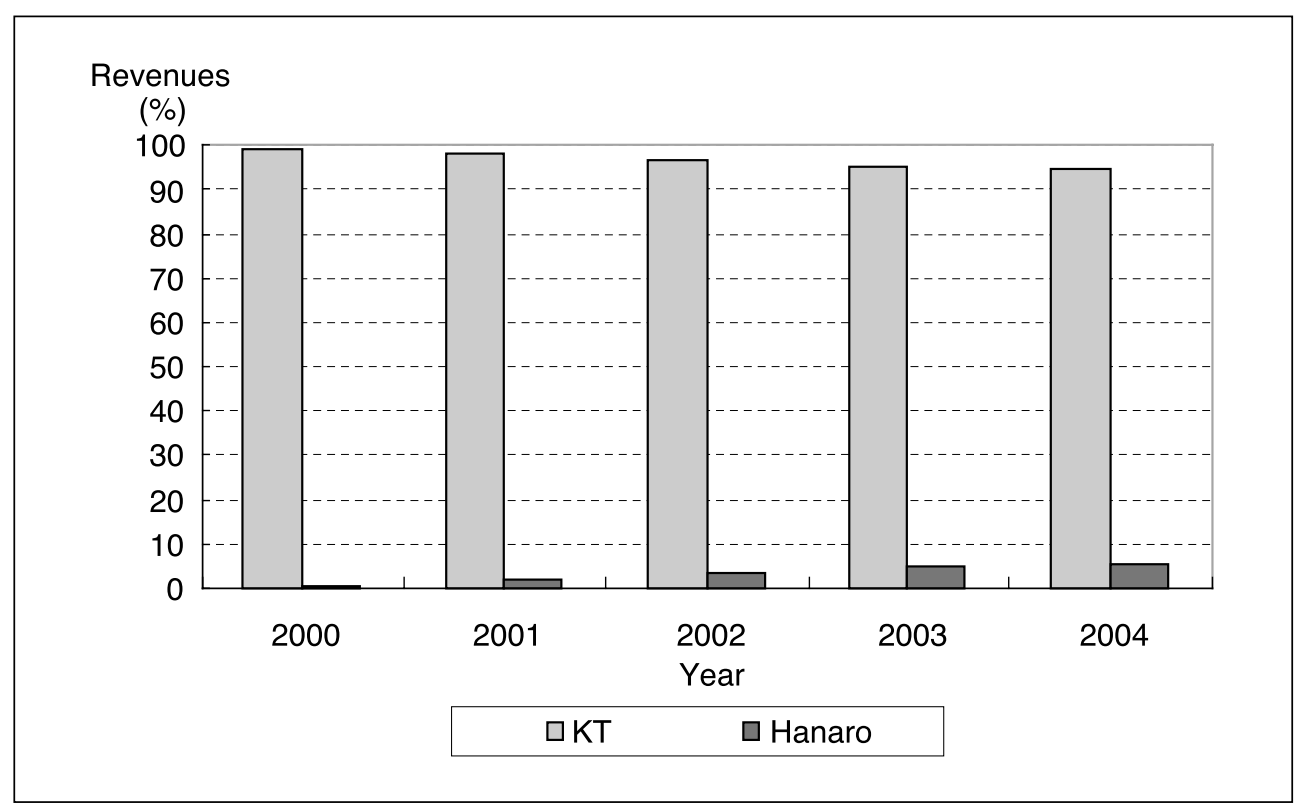

Source: KFTC

The Korean Journal of Policy Studies 
continued to gain in all three categories.

There is insufficient information to infer whether these changes were the result of Hanaro's competitiveness or of MIC's so-called effective competition policy. However, institutional changes in the industry indicate that KT was not expected to enjoy dominance as it had in the past. First, MIC introduced the policy of Local Loop Unbundling in 2003 and thus facilitated service-based competition. Second, Local Number Portability was scheduled to be introduced in 2003, and was expected to reduce consumers' switching costs. Indeed, as shown in figure 4, the number of consumers who switched between competing carriers of fixed-line telecommunications service has increased year after year, although the number of total subscribers has remained almost unchanged. In 2004, 183,267 consumers switched between carriers, while in 2006, 593,324 consumers switched. Figure 4 also indicates that more consumers switched from KT to Hanaro.

Figure 4. Users of Local Number Portability

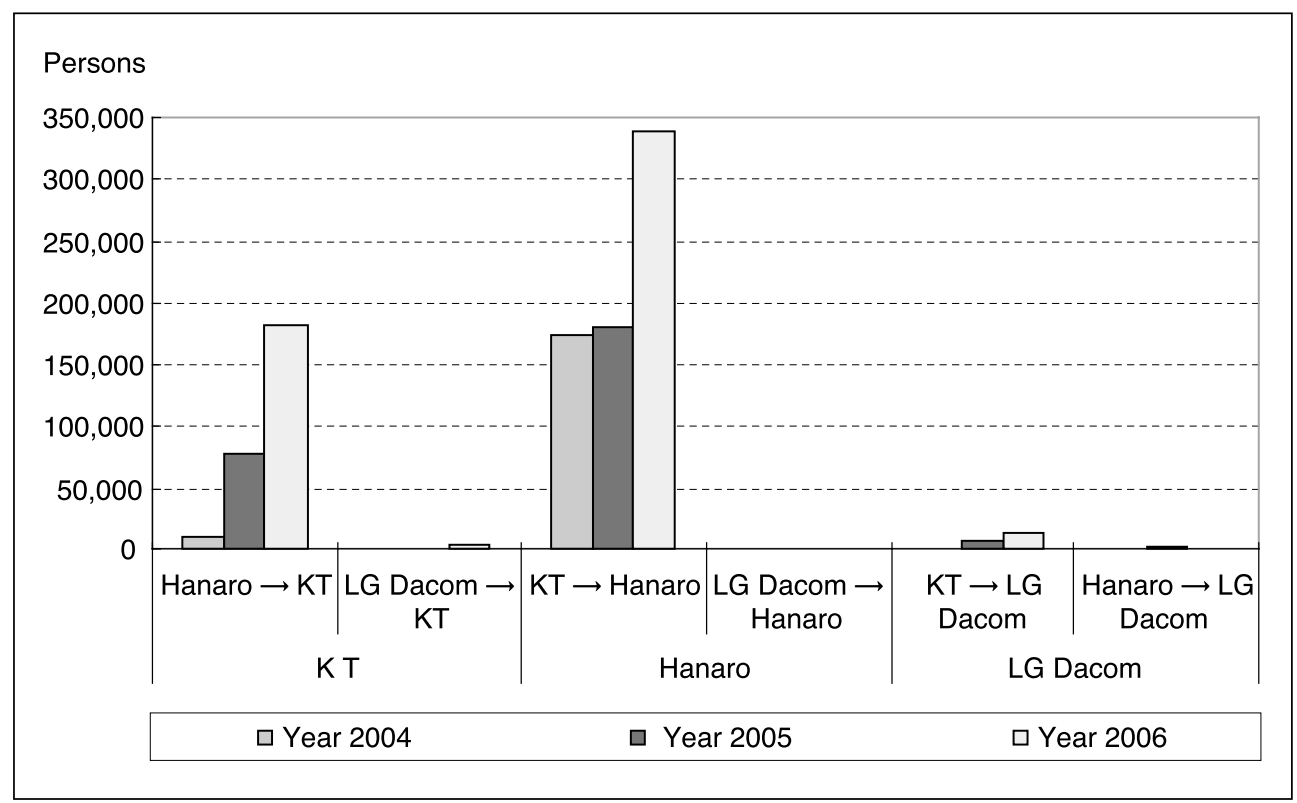

Source: MIC

In addition, the emerging competitors have expanded their facilities and improved the quality of their services. As a result, consumers perceived no significant difference in the quality of services between KT and Hanaro. As shown in figure 5, KT and Hanaro have similar scores in the National Consumer Satisfaction Index as reported 
Figure 5. National Consumer Satisfaction Index

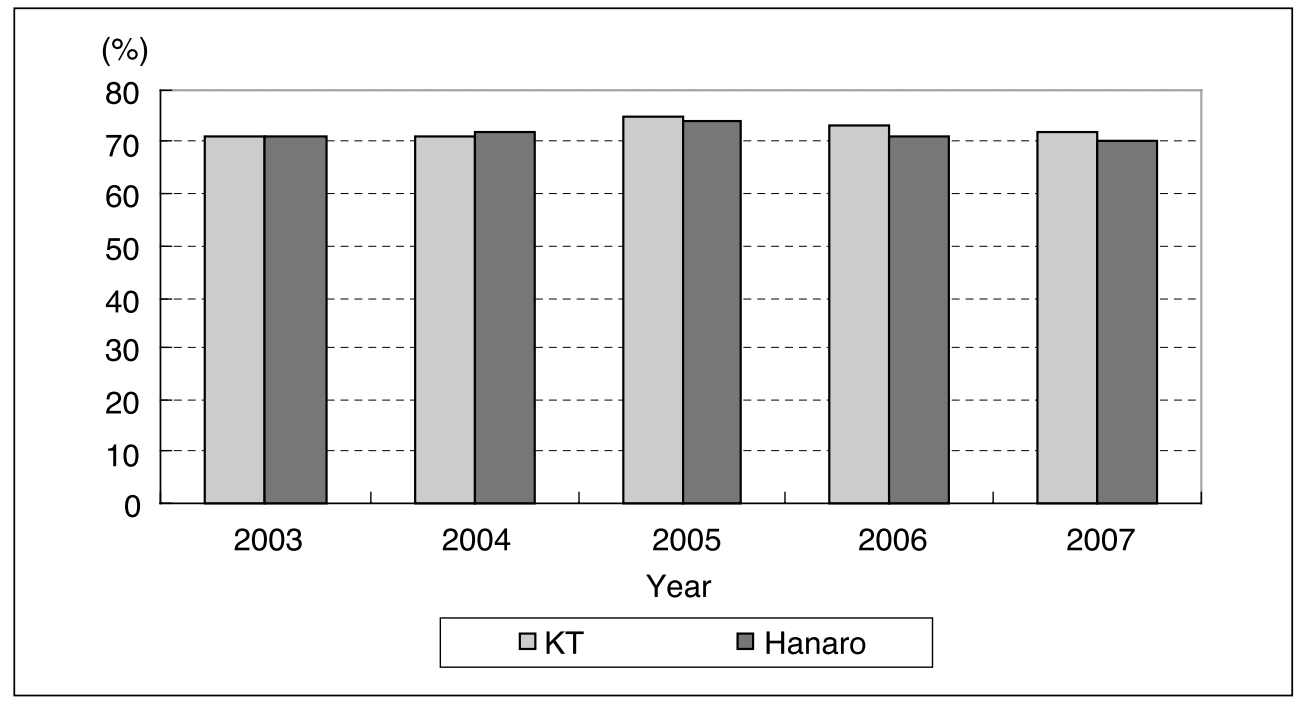

Source: Korea Productivity Center

Figure 6. Revenues from Fixed-Line and Mobile Telecommunications Service

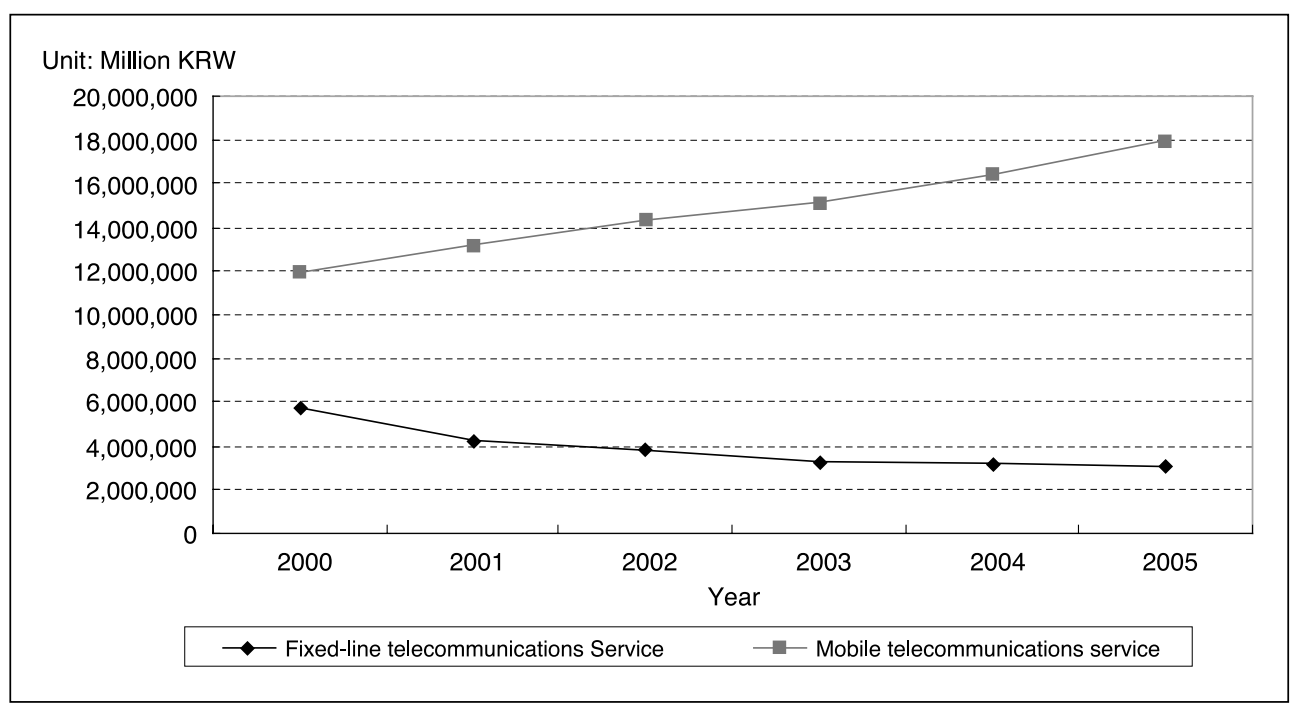

Source: IT Statistics of Korea (www.itstat.go.kr)

by the Korea Productivity Center.

The competition from mobile communications services and the potential competition from VoIP (Voice over Internet Protocol) might also constrain KT's monopoly 
power in the fixed-line market. Figure 6 illustrates how revenues from mobile communications service have increased since 2000 while revenues from fixed-line service decreased. Several studies (for instance, Byun et al. 2003) indicate increasing and significant substitutability between mobile and fixed-line calls.

The foregoing evidence indicates that MIC's first concern might be unfounded at the time (late 2002). Indeed, MIC seems to have more concerned about the second possibility, aggressive price competition leading to the exit of competitors from the market. However, that concern appears to have been groundless as well.

Apparently, the administrative guidance was implemented in response to the dominant firm's (KT's) new price policy in September 2002. However, this price policy

Figure 7. Hanaro's Revenues and Operating Profits

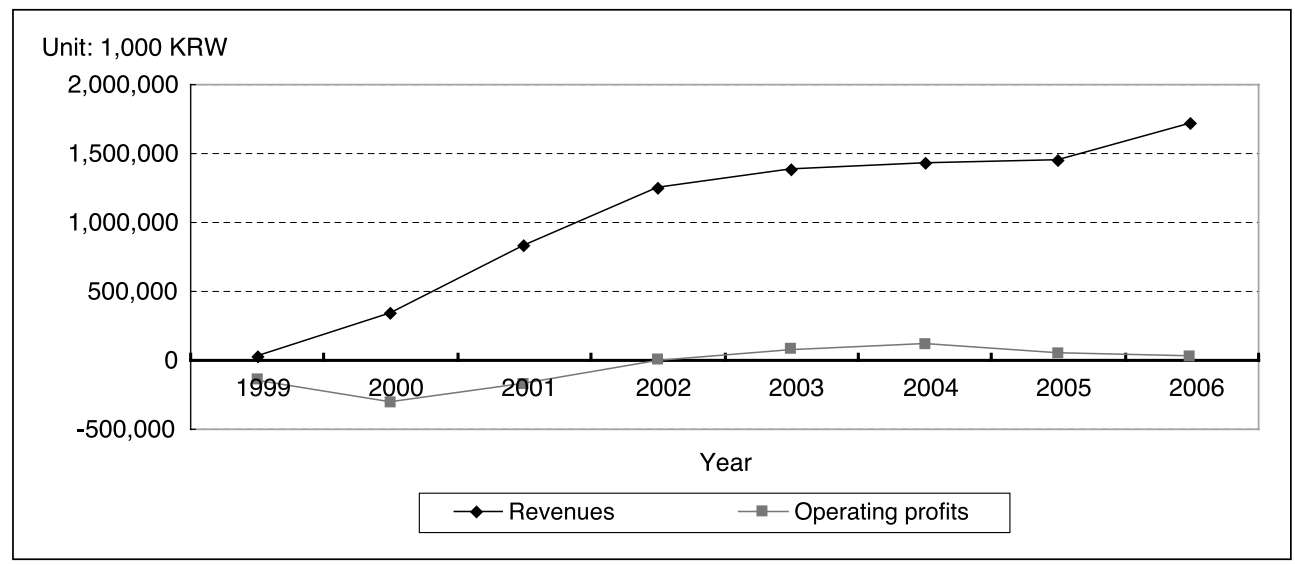

Source: Financial Supervisory Service

Table 1. Pricing Structure of KT and Hanaro as of June 2003

\begin{tabular}{l|l|l}
\hline & \multicolumn{1}{|c}{ KT } & \multicolumn{1}{c}{ Hanaro } \\
\hline Subscription fee & $60,000 \mathrm{KRW}$ & None \\
\hline Basic fee & $5,200 \mathrm{KRW}$ & Basic service: 3,500 KRW \\
\cline { 2 - 3 } & $39 \mathrm{KRW}$ & Bundled service: $1,000 \mathrm{KRW}$ \\
\hline Rate per 3 minutes & No & Yes \\
\hline Discounted rate available? & $2,500 \mathrm{KRW}$ & $1,000 \mathrm{KRW}$ \\
\hline Caller ID & $\begin{array}{l}\text { Regular: } 15.63 \mathrm{KRW} \\
\text { Discounted: } 14.81 \mathrm{KRW} \\
\text { Special: } 13.99 \mathrm{KRW}\end{array}$ & $\begin{array}{l}\text { Regular: } 15.00 \mathrm{KRW} \\
\text { Night: } 14.00 \mathrm{KRW} \\
\text { Late Night: 13.00 KRW }\end{array}$ \\
\hline $\begin{array}{l}\text { LM usage fee } \\
\text { (per 10 seconds) }\end{array}$ &
\end{tabular}

Source: KFTC 
was met by Hanaro (see pages 6-7 of KFTC Decision 2005). Despite these changes in price policies, Hanaro's financial status improved in 2002 and 2003. As shown in figure 7, Hanaro's revenue continued to increase and it began to make a profit in 2002. KT's new price policy might have been a response to the introduction of Local Number Portability in 2003, and not predatory pricing to drive the rival out of the market.

Moreover, prior to the collusive agreement between the two firms, it was Hanaro that engaged in more aggressive pricing. As shown in table 1, Hanaro charged the same or lower fees and call rates in every category. Indeed, a dominant firm would suffer greater loss of revenues from a severe price competition because it has higher sales. Table 1 and figure 7 together suggest no evidence that Hanaro might have been forced to exit the market by KT's initiation of aggressive pricing in September 2002.

\section{AN ALTERNATIVE PRO-COMPETITIVE POLICY}

MIC's effective-competition policy is based on concerns that small or emerging competitors may not be able to constrain a dominant firm from wielding monopoly power or to survive severe price competition from the dominant firm. However, the evidence from the KT-Hanaro case does not support this concern, at least regarding the market for fixed-line telecommunications service around the end of 2002. Although there is not enough information to determine whether the situation at the end of 2002 was the result of MIC's policy in earlier years, our analysis casts doubt on the effectiveness of the ministry's administrative guidance (which it typically employs as part of its effective-competition policy) around the end of 2002.

Indeed, MIC's administrative guidance promotes a policy of "managed competition" rather than a true "effective competition." Although this may succeed in the beginning, the case study presented in the previous section indicates that it is difficult to abolish the policy even when effective competition is present in the market. A drawback of the policy is that it risks facilitating collusion, and it is unnecessary to reemphasize the harms that collusion inflicts on society.

Hence, we suggest an alternative policy for regulating a market in which there exists a dominant firm and the regulatory authority plans to permit entry into the market-for example, the Wibro case. To promote competition, the regulatory authority may choose a policy that creates a level playing field for fledgling competitors. To accomplish this in the telecommunications field, equal (cost-adjusted) quality of service may be critical.

Equal (cost-adjusted) quality means that the dominant firm and its competitors can provide the same quality of service at the same cost, or that quality differences can be 
justified by cost differences. For instance, in mobile communications, equivalent radio spectrum bands can be assigned to new entrants. In extreme cases in which a certain facility of the incumbent, dominant firm cannot be replicated by the new entrant's investments, the regulatory authority may either order the dominant firm to sell part of the facility or enforce the entrant's access to it.

Even with a level playing field, the dominant firm may engage in predatory pricing in order to drive out the fledgling competitor. However, predatory pricing will inflict more harm on the dominant firm. Moreover, in a regulated industry, it is more likely to be detected by the regulatory authority and can be punished under the law.

The regulatory authority that seeks to ensure a level playing field for entrants to an industry may have to pay more attention to possible collusion in the industry. As predicted in theoretical studies, a level playing field may lead in the end to similar market shares for the incumbent and new entrants (Nayyar 2001), and the firms to produce same quality of service may be relatively easier to collude (Balra 2000).

\section{CONCLUSION}

This paper critically reviewed administrative guidance as a part of MIC's effectivecompetition policy by looking at the collusion between KT and Hanaro in the fixedline telecommunications service market. Analysis showed that the evidence does not support administrative guidance as a means of promoting effective competition. Instead, this practice turned out to facilitate collusion between the dominant firm and the emerging competitor. Hence, as a future policy recommendation, we suggest an alternative pro-competitive policy that provides a level playing field to emerging competitors from the beginning. Once a level playing field is established, there is still a risk of predatory pricing and collusion, and the regulatory authority may have to focus on that possibility.

\section{REFERENCES}

Armstrong, M. (1998). Network Interconnection in Telecommunications. The Economic Journal, 108(448): 545-564.

Averchy, H., \& Johnson, L. L. (1962). Behavior of the Firm under Regulatory Constraint. American Economic Review, 52(5): 1052-1069.

Baranes, E., \& Bourreau, M. (2005). An Economist's Guide to Local Loop Unbundling. Communications \& Strategies, 57(1): 13-31. 
Barla, P. (2000). Firm size inequality and market power. International Journal of Industrial Organization, 18(5): 693-722.

Baumol, W., \& Sidak, G. (1994). Toward Competition in Local Telephony. The MIT Press.

Baumol, W., \& Willig, R. (1981). Fixed Costs, Sunk Costs, Entry Barriers, and Sustainability of Monopoly. Quarterly Journal of Economics, 96(3): 405-431.

Bourreau, M., \& Doğan, P. (2004). Service-Based vs. Facility-Based Competition in Local Access Networks. Information Economics and Policy, 16(2): 287-306.

Brennan, T. (1995). Is the Theory behind US v. AT\&T Applicable Today? Antitrust Bulletin, 40: 455-482.

Byun et al. (2003). An Empirical Study on the Substitutability of Electronic Telecommunication Service Against Mobile Telecommunication Service. Research Report 03-15, Korea Information Society Development Institute.

Choi, Seon Gyu. (2004). Fixed Mobile Convergence and Regulatory Policy; Asymmetric Regulation Under Fixed Mobile Convergence: Fair Competition or Managed Competition? Korea Journal of Telecommunications Policies, 11(1): 1-22.

Farrell, J., \& Shapiro, C. (1988). Dynamic Competition with Switching Costs. Rand Journal of Economics, 19(1): 123-137.

Hausman, J. A., \& Sidak, G. (2005). Did Mandatory Unbundling Achieve Its Purpose? Empirical Evidence from Five Countries. Journal of Competition Law and Economics, 1(1): 173-245.

Huber, Kellog, \& Thorne. (1999). Federal Telecommunications and Law. Aspen Law $\&$ Business.

Huber, P. W., Kellog, M. K., \& Thorne, J. (1993). The Geodesic Network II. Washington, DC: U.S. Department of Justice, Antitrust Division.

Jeon, Young Seo. (1995). An Empirical Study on the Natural Monopoly of Telecommunications Industry. Korea Journal of Telecommunications Policies, 2(1): 115-148.

. (2000). The Substitutability of Electronic Telecommunication Service Against Mobile Telecommunication Service. International Economic Journal, 6(2): 175-193.

Knittel, C. R., \& Stango, V. (2003). Price Ceilings as Focal Points for Tacit Collusion: Evidence from Credit Cards. American Economic Review, 93(5): 1703-1729.

Korea Fair Trade Commission. (2005). Unfair Pact by Four International Telephone Service Providers. Resolution No. 2005-331. . (2005). Unfair Pact by Two Local Telephone Service Providers. Resolution No. 2005-130.

Laffont, J., \& Tirole, J. (1996). Creating Competition through Interconnection: Theory 
and Practice. Journal of Regulatory Economics, 10(3): 227-256. . (2000). Competition in Telecommunications. The MIT Press.

Lee, Bong-Ho. (1999). Competition in Local Telecommunications Services Market and Price Regulation. Korea Journal of Telecommunications Policies, 6(2) 157-184.

Milgrom, P., \& Robert, J. (1982). Predation, Reputation and Entry Deterrence. Journal of Economic Theory, 27(2): 280-312.

Nayyar, A. (2004). Entry in a Dynamic Model with Equilibrium Price Dispersion with an Application to the Market for Long-Distance Telephone Service. Journal of Public Economic Theory, 6(4): 577-592.

Noll, R. (1995). The Roll of Antitrust in Telecommunications. Antitrust Bulletin, 40: 501-528.

Rhee, Moon-Ji. (2001). Economic Regulation and Antitrust Immunity. Korea Journal of Commercial Law, 20(1): 693-722.

Weiss, J. R., \& Stern, M. L. (1998). Serving Two Masters: The Dual Jurisdiction of the FCC and the Justice Department over Telecommunications Transactions. CommLaw Conspectus, 6: 195-212.

Witteloostuijn, A., \& Maks, J. A. H. (1998). Workable Competition and the Barrier Market. European Journal of Political Economy, 4(1): 117-135. 